BULLETIN Bulletin hispanique

HISPANIQUE Université Michel de Montaigne Bordeaux

120-1 | 2018

Varia

\title{
Olvido y recuperación de un proyecto cultural de alcance transatlántico
}

claves bibliográficas para el estudio de la revista Alfar

Oubli et récupération d'un projet culturel de portée transatlantique :

clefs bibliographiques pour l'étude de la revue Alfar

Oblivion and retrieving of a cultural project of transatlantical range:

bibliographical keys for studying the magazine 'Alfar'

\section{Bernat Padró Nieto}

\section{(2) OpenEdition}

Journals

Edición electrónica

URL: https://journals.openedition.org/bulletinhispanique/5612

DOI: 10.4000/bulletinhispanique.5612

ISSN: 1775-3821

Editor

Presses universitaires de Bordeaux

Edición impresa

Fecha de publicación: 30 junio 2018

Paginación: 147-162

ISBN: 979-10-300-0298-0

ISSN: 0007-4640

Referencia electrónica

Bernat Padró Nieto, «Olvido y recuperación de un proyecto cultural de alcance transatlántico», Bulletin hispanique [En línea], 120-1 | 2018, Publicado el 01 enero 2022, consultado el 08 enero 2022. URL: http://journals.openedition.org/bulletinhispanique/5612 ; DOl: https://doi.org/10.4000/ bulletinhispanique.5612 


\title{
Olvido y recuperación de un proyecto cultural de alcance transatlántico: claves bibliográficas para el estudio de la revista Alfar
}

\author{
Bernat Padró Nieto \\ Universitat de Barcelona
}

La revue Alfar (La Corogne) a été l'un des projets culturels les plus remarquable des années vingt dans le monde hispanophone. Regroupant dans ses pages écrivains et artistes marquants de l'époque, elle établit un dialogue entre les littératures ibériques et hispaniques de part et d'autre de l'Atlantique. La Guerre Civile espagnole et l'exode massif de la plupart de ses collaborateurs firent tomber Alfar dans un oubli que seuls quelques rares chercheurs ont tenté de réparer.

Mots-clés : Alfar, études transatlantiques, Julio J. Casal.

La revista coruñesa Alfar fue uno de los proyectos culturales más relevantes de los años veinte en el ámbito hispanoamericano. Congregó en sus páginas a los escritores y artistas plásticos más importantes del momento, estableciendo un diálogo entre las literaturas ibéricas y las hispánicas a través del Atlántico. La Guerra Civil española y el exilio masivo de la mayoría de sus colaboradores sumieron a Alfar en un olvido que apenas algunos pocos estudiosos han intentado revertir.

Palabras clave : Alfar, estudios transatlánticos, Julio J. Casal.

The magazine 'Alfar' from La Coruña, was one of the most outstanding cultural projects of the twenties in the Hispanic world. It gathered in its pages the most important writers and artists of the time, establishing an intellectual dialogue between the Iberian literatures and the Hispanic literatures across the Atlantic. The Spanish Civil War and the massive exodus of most of the magazine's contributors made 'Alfar' fall into an oblivion which just a few scholars have attempted to reverse.

Keywords : Alfar, Transatlantic Studies, Julio J. Casal. 
$\mathrm{C}$ uando a principios de 1926 el Bulletin Hispanique publicó una nota de elogio hacia Alfar, la revista coruñesa se encontraba en la cumbre de su prestigio y proyección internacional. No había en toda Espańa otra revista que se le pudiera comparar. La bilbaína Hermes había desaparecido en junio de 1922, La Pluma en junio de 1923 y España en marzo de 1924. Estas revistas presentaban además un carácter misceláneo alejado del programa de Alfar, dedicada fundamentalmente a la creación. Por ello tampoco se la podía comparar con Revista de Occidente, una revista de pensamiento. Documento de descomposición del ultraísmo y tribuna del formalismo novoclasicista; puente entre escritores de ambos lados del Atlántico; plataforma en la que jóvenes como Alberti, Bergamín, Dalí o Buñuel convivían con autores consagrados como Antonio Machado, Azorín o Gómez de la Serna; gran aparador de lo mejor que en arte plástico se producía en España; la revista Alfar se convirtió a lo largo de cinco años de periodicidad mensual -salvo alguna ocasión-en un referente inexcusable en el campo literario español. Los méritos de Alfar eran glosados por el historiador Manuel Núńez de Arena en la nota firmada el 10 de febrero y publicada en la sección «Chronique» del Bulletin Hispanique:

Alfar. - El que una revista puramente de letras y artes, es decir, sin mezcla de actualidad, ni de sucesos, ni de política, logre en España llegar a los cinco años de edad, es algo de carácter maravilloso. Alfar es el único ensayo que conozco de semejante perdurabilidad. Admirablemente presentada, con exquisito gusto, con cierto eclecticismo en la colaboración, que permite leer, junto a Concha Espina, a Guillermo de Torre, y al lado de las prosas de Hernández Catá y de Gabriel Miró, los versos de Jules Supervielle (en francés), o la defensa del superrealismo de Pierre Picón; con artículos o poesías de Ors, Machado y otros jóvenes o consagrados; además, ornada de páginas de arte en las que se siguen con suma competencia y precisión las exposiciones de París y de Madrid y en las que se estudia a los nuevos artistas y las modernas tendencias, es hoy la sola tentativa (la Revista de Occidente tiene otro carácter) de periódico bello, asequible, incluso económicamente, a un gran público intelectual. Todo ello es debido a la fina labor de dirección y de crítica de un escritor uruguayo, D. Julio J. Casal. Para que el prodigio resulte todavía mayor, se ha de añadir que Alfar no se publica en Madrid ni en Barcelona, sino en La Coruńa, frente al mar, como a mitad de camino de América y de Espańa, los dos campos en que quiere sembrar y en los que siembra. Serenamente, recogiendo adhesiones fervorosas, emprendió su ruta cultivando con el pensamiento alto y el gusto depurado las manifestaciones más nobles de la literatura y de las artes. No ha cejado en su empeño y cada mes aporta escogidamente un rico botín. ${ }^{1}$

Bien señalaba Núñez de Arena al poeta Julio J. Casal como el principal artífice de Alfar. Poeta y diplomático uruguayo, cónsul de su país en La Coruña desde 1913, después de haberlo sido durante cuatro años en La Rochelle, fue uno de los fundadores en 1920 de Casa América-Galicia, además de su secretario general desde la fundación. A medida que fue ganando influencia en la institución fue interviniendo en el boletín que ésta publicaba, hasta llegar

1. Manuel Núñez de Arena, "Chronique», Bulletin Hispanique, volumen 28, n 1, 1926, p. 112. 
a ser su director a finales de 1922 y, pocas semanas después, presidente de la institución. Con Casal a la cabeza, la Revista de Casa América-Galicia experimentó un proceso de depuración de contenidos -y cambio de nombre- hasta convertirse a la altura de 1926 en la principal revista de creación de Espańa. No era la primera vez que aparecía mencionada en una publicación francesa de prestigio. El 15 de enero de 1925 Francisco Contreras había dejado una nota elogiosa en el Mercure de France:

Alfar est le titre d'une belle revue de lettres et d'art, très bien illustrée, qui paraît à la Corogne (Espagne). Dirigée par le poète uruguayen J. Casal, elle réunit la collaboration de nombreux écrivains jeunes d'Amérique et d'Espagne. Dans les derniers numéros, nous remarquons un beau poème de l'excellent écrivain catalan Alfons Maseras, «Huerto Vedado » et une page curieuse du poète uruguayen M. Ballesteros, «El Sultán pasa revista.$^{2}$

La mención en el Bulletin Hispanique significaba en todo caso el reconocimiento por parte de la Academia. Así lo entendió Alberto Insúa, que en abril de 1926 informó de la nota en primera página del diario La Voz:

Había llegado la hora de decirlo al público que en las ánforas de Alfar hay vino y agua, agua y miel, y agua sola, purísima, para todos. Le había llegado la hora al poeta Casal -icinco años de favor y de paciencia!- del elogio en el Bulletin Hispanique y en LA VOZ; del elogio erudito, que leerán los sabios del mundo entero, y del elogio en el rotativo, que lee en Espańa todo el que sabe leer.

Enhorabuena al alfarero infatigable, curioso, soñador $\mathrm{y}$ «armonizador»... ${ }^{3}$

$\mathrm{Al}$ año siguiente era Les Nouvelles Littéraires quien dedicaba una nota a Julio J. Casal ${ }^{4}$, cuyos méritos y los de la revista fueron siempre juntos en un solo prestigio. Esta vez fueron La Gaceta Literaria ${ }^{5}$ y el periódico La Libertad ${ }^{6}$, éste con artículo de Juan Chabás, asiduo colaborador de Alfar, los que se hicieron eco de la noticia. Ambas publicaciones señalaban que la revista se encontraba interrumpida temporalmente por el viaje de Casal a Montevideo. En efecto,

2. Francisco Contreras, «Lettres Hispano-Américaines», Mercure de France, no 638, tomo CLXXVII, 15 de enero de 1925, p. 559.

3. Alberto Insúa, «Un alfarero infatigable», $L a$ Voz, Madrid, 12 de abril de 1926, p. 1.

4. Adolphe Falgairolle, "Julio J. Casal», Les Nouvelles Littéraires, París, 1 de enero de 1927.

5. La nota decía: «En "Les Nouvelles Literaires" [sic], del 1 de Enero, el hispanista Adolphe Falgairolle consagra un elogioso comentario al poeta Julio J. Casal, haciendo resaltar la noble significación de su revista Alfar, que este gran "animador" publica en La Coruña; publicación actualmente interrumpida por el viaje de su director a Montevideo, pero que, según nuestras noticias, reaparecerá, a su regreso, editada en Madrid». Ubiquens, «Las letras Españolas en el Extranjero", La Gaceta Literaria, Madrid, no 3, 1 de febrero de 1927, p. 1.

6. Escribía Chabás: "Les Nouvelles Littéraires” publica un artículo sobre Julio J. Casal, el poeta uruguayo que fundó y dirigió la revista "Alfar", por ahora suspendida, y elogia su doble labor de director y de poeta. Muy justo elogio a quien, como Casal, supo poner todos sus empeños en el logro de los mejores entusiasmos. Y a más de su obra personal, hizo esa revista que, durante algún tiempo, casi fué la única con la que había que contar». Juan Chabás, "Revistas», La Libertad, Madrid, 7 de enero de 1927, p. 7. 
Casal planeó durante meses reiniciar su revista, incluso trasladarla a Madrid y dotarla todavía de mayor empaque literario, pero todo quedó en proyecto, ya que nunca regresaría a España. En 1929 reinició Alfar en Montevideo, ahora sin apoyo económico ni institucional, y fue apareciendo de forma irregular hasta su último número en enero de 1955, pocos días después de la muerte de Casal.

La consagración de Casal a mediados de los años veinte y el renombre internacional de Alfar fueron sin embargo efímeros, pues en el momento de la cima de su celebridad decidió abandonar el proyecto y regresar al Uruguay, y después de la Guerra Civil española su recuerdo se borró debido a la muerte o el exilio de los que lo conocieron a él y a su Alfar.

Tras el olvido en que quedó sumida después de la Guerra Civil, la primera mención a Alfar en España la hizo en 1944 José María de Cossío, antiguo colaborador de la revista ${ }^{7}$, que atribuyó a la revista «el más alto valor documental, y no es excesivo considerarla como el panorama más cabal de la revuelta vida poética de aquel momento» (Cossío 1944: 15-16). Hasta 1952 Alfar no volvería a ser mencionada, esta vez en Medio siglo de publicaciones de poesía en España de Rafael Santos Torroella, estudio pionero en España sobre las revistas culturales. Como vendría siendo habitual debido al difícil acceso de sus contenidos, algunas de las fechas que proporciona son erróneas, debido a la fuente documental, que no es otra que Literaturas Europeas de Vanguardia (1925) de Guillermo de Torre. En los años 60 las referencias a la revista coruñesa aumentaron levemente. En 1963 Gloria Videla incluyó Alfar en el corpus de las revistas ultraístas en su libro El ultraísmo ${ }^{8}$, y en 1965 Guillermo de Torre mantenía ese criterio en Historia de las literaturas de vanguardia, libro que demasiadas veces se ha tomado como referente a pesar de contener incontables errores, especialmente en relación a las revistas de la época. En él dedicaba unas palabras a la revista de Casal:

la suma final de estas efímeras revistas [ultraístas] vino a realizarse en otra de más larga vida, Alfar, también muy mezclada en su primera fase [...]. Con algo de magazine literario, muy bellamente ilustrado, concediendo amplio espacio a artes plásticas, en Alfar se reúnen los que llamaríamos «supervivientes» del primitivo ultraísmo con otros escritores muy diversos, lográndose siempre, no obstante, un estimable nivel. (Torre 2001: 550)

$\mathrm{Al}$ año siguiente un artículo de Valeriano Bozal dedicado a «La renovación artística de 1925 en España» apuntaba la importancia de la revista coruñesa en el ámbito plástico de los años veinte. De ella decía que era una de las tres revistas independientes de la época, junto a La Gaceta Literaria y la Gaseta de

7. Cossío había colaborado con algunas reseñas en los números 51, 55 y 59 de Alfar, y en el 60 dedicó un estudio a la pintura de Cristóbal Hall, que le realizó un retrato que fue publicado en el mismo número.

8. Gloria Videla, El ultraísmo: estudios sobre movimientos poéticos de vanguardia en España, Madrid, Gredos, 1963. 
les Arts $^{9}$. Y en 1969 José María de Cossío volvía a recordar Alfar en su texto "Recuerdos de una generación poética»:

Los poetas más conocidos entonces de ella colaboran desde 1922 en la revista Alfar, de la Coruña, que dirigía y orientaba con excelente gusto y acierto el poeta americano Julio J. Casal. En ella figuran, junto a los que han de constituir la generación del 27, los más extremados ultraístas, en franco fin de escuela. Ha cedido poco su auge y todos sufren el contagio inevitable, pero otro tipo de poesía anuncia el relevo. En mezcla confusa se ofrecen los ultraístas, para los que ha sonado su hora final, con los que inician un nuevo tipo de poesía, y son los que formaron el grupo de revistas de que pasaré en seguida a ocuparme, y que señalan el advenimiento de una poesía nueva, cuyo auge puede hacerse coincidir sin violencia con la de la celebración del tercer centenario de Góngora, que es el hecho literario que a mi entender da unidad, aunque pasajera y precaria, al grupo formado por los más selectos y que marca una época en el quehacer de los poetas jóvenes, unánimemente respetado. En Alfar colaboran algunos tan significativos como Jorge Guillén, Rafael Alberti, Juan González del Valle, Rogelio Buendía, Adriano del Valle, y otros muchos que habrán de ser infaltables en las nóminas de las nuevas revistas. Alfar merece un recuerdo afectuoso, no sólo por haberse iniciado allí poetas que han de ser inevitablemente considerados al hablar de esta generación cuya obra poética me ocupa, sino porque la dignidad literaria y gráfica de esa revista, en la que colaboraban a partes iguales poetas americanos y peninsulares, es el lugar de partida del grupo que ha de formar la generación del centenario de Góngora. Claro es que muy anteriormente eran ya conocidos esos poetas, pero la primera tribuna, y dirigida hacia ellos, que tuvieron, fue la de las páginas de la excelente revista gallega. (Cossío 1970: 193)

Cossío situaba acertadamente la revista en su dimensión hispanoamericana y, a diferencia de Videla y de Torre, desplaza su interés hacia las tensiones entre un ultraísmo en retirada, la construcción del formalismo clasicista y el inicio del cansancio de la poesía excesivamente intelectualizada. En este periodo aparecieron en el Río de la Plata algunos textos en memoria de Casal que apenas tuvieron repercusión en España. Entre ellos destacamos Diálogo con Julio J. Casal de Juvenal Ortiz Saralegui, un volumen de homenaje aparecido en 1955, a los pocos meses de la muerte del director de Alfar.

\section{UN ESTUDIO PIONERO EN LOS SETENTA Y LA ECLOSIÓN EN LOS OCHENTA}

El estudio pionero dedicado íntegramente a Alfar lo llevó a cabo Víctor García de la Concha en un artículo titulado "Alfar, historia de dos revistas literarias», publicado en 1971 Cuadernos Hispanoamericanos. García de la Concha hacía una aproximación a Alfar y a un proyecto previo, la revista Vida, impulsada por el mismo Casal y por el grupo de intelectuales coruñeses. La

9. «Salvo tres de las revistas citadas, las restantes son órganos de una determinada tendencia estética, ya sea el ultraísmo, ya el surrealismo más o menos depurado. Las tres revistas independientes son La Gaceta Literaria, Alfar y Gaseta de les Arts». Valeriano Bozal, "La renovación artística de 1925 en España», Cuadernos Hispanoamericanos, Madrid, no 194, 1966, p. 251. 
descripción de los contenidos de Alfar y de su trayectoria es minuciosa y exacta, aportando así un documento fundamental para el estudio de «una de las más apasionantes aventuras literarias de los años veinte». Como el propio García de la Concha afirmaba al inicio de su texto, la época comprendida entre el fin del ultraísmo y la emergencia de nuevos moldes poéticos hacia 1927 era muy poco conocida. Por ello tiene enorme mérito el libro de Anthony Geist La poética de la generación del 27 y las revistas literarias: de la vanguardia al compromiso (19181936), aparecido en 1980, cuyo desarrollo argumental contempla numerosos textos de Alfar, mostrando hasta qué punto no es posible comprender los debates estéticos de la época sin la revista coruñesa. Hay que tener en cuenta que en 1980 el acceso a los contenidos de la revista era limitadísimo. La recuperación del corpus de Alfar para los estudios literarios y artísticos tuvo en César Antonio Molina su gran promotor. La labor por él realizada en los años ochenta sigue siendo a día de hoy la referencia fundamental de los estudios posteriores sobre Alfar. Molina editó el facsímil de la etapa española de la revista, publicó el primer -y hasta hoy único- estudio amplio y documentado de sus contenidos literarios, y promovió una serie de exposiciones. En 1983 aparecieron los cuatro primeros tomos de la edición facsimilar. El quinto, que incluía trabajos del propio Molina y de Juan Manuel Bonet, nunca llegó a editarse ${ }^{10}$. Al año siguiente publicó La revista Alfar y la prensa literaria de su época (1920-1930), referencia inexcusable para el estudio de la revista coruñesa. También en 1984 se celebró la exposición Alfar y su época, comisariada por el mismo Molina, con un importante contingente documental ${ }^{11}$. La exposición tuvo lugar en La Coruña y se trasladó a Madrid y Bilbao. Los periódicos $E l$ País, $A B C$ y La Vanguardia, curiosamente los tres rotativos españoles activos en tiempos de Alfar, publicaron artículos que elogiaron la labor de Molina y la exposición, que se convirtió en un acontecimiento cultural de primer orden, con la presencia de Francisco Ayala, Rafael Alberti, Premio Cervantes ese mismo año, Mario Benedetti, que publicó un artículo en El País ${ }^{12}$, Gonzalo Torrente Ballester y el futuro Premio Nobel Camilo José Cela, entre otros. Manuel Rivas publicó tres artículos en El País sobre el acontecimiento ${ }^{13}$, Miguel García Posada reseñó el facsímil en $A B C$ Cultural ${ }^{14}$, y Juan Manuel Bonet hizo lo mismo en La Vanguardia ${ }^{15}$. En 1984 se celebraron en Montevideo los treinta

10. Según el propio Bonet, su texto sobre el aspecto plástico de la revista ha sido citado en varias ocasiones como si hubiera visto la luz (Bonet 1995: 39).

11. Los libros y revistas expuestos procedían de las bibliotecas de Juan Manuel Bonet, Pilar Cebreiro de Possi, Luis Alberto de Cuenca, José Esteban, José Luis Jover, Abelardo Linares, César Antonio Molina, Francisco Rivas, Rafael Santos Torroella, Andrés Trapiello, Ramón Borrás, la Real Academia Gallega, el Museo Carlos Maside y la librería Gulliver de Madrid.

12. Mario Benedetti, «Coruñeses y montevideanos», El País, 30 de enero de 1984.

13. Los artículos fueron «Edición facsímil de la revista cultural "Alfar"», El País, 10 de julio de 1983; «La recuperación de "Alfar" revela una insólita experiencia cultural en la periferia», $E l$ País, 14 de enero de 1984; y "Reivindican en La Coruña el carácter abierto y plurilingüe de la revista literaria "Alfar"”, El Pais, 23 de enero de 1984.

14. Miguel García Posada, "Alfar», ABC cultural, 11 de febrero de 1984.

15. Juan Manuel Bonet, «Memoria de "Alfar" y de una Coruña cosmopolita», La Vanguardia, 
años de la muerte de Casal, con motivo de lo cual se inauguró el 7 de diciembre una "Muestra Bio-Bibliográfica» titulada "Julio J. Casal. El poeta y su revista Alfar» elaborada con materiales provenientes de los fondos bibliográficos de la Biblioteca Nacional y del Archivo «Julio J. Casal» donado por la familia. El verano del año siguiente Lily Litvak reseñó la edición facsimilar en Hispanic Review, y en 1987 apareció Mi padre Julio J. Casal, escrito por su hija Selva y publicado en la Biblioteca Alfar, fundada por Casal en Montevideo (Casal Muñoz 1987). Dos años después, César Antonio Molina publicó en Revista de Occidente el artículo "Alfar: una revista entre dos mundos», extraído de su tesis doctoral titulada Historia de la prensa literaria en España desde comienzos de siglo hasta la guerra civil, defendida en la Facultad de Ciencias de la Información de la Universidad Complutense de Madrid el año anterior. También en 1988 la revista Anales de literatura hispanoamericana publicó un artículo de Miguel Losada titulado "Presencia de la literatura hispanoamericana en las revistas espańolas de vanguardia: 1918-1939» en el que ocupa un lugar destacado la revista coruñesa. Pero el estudio más relevante sobre Alfar en 1988 lo constituye un capítulo del libro de Andrés Soria Olmedo Vanguardismo y crítica literaria en España (1910-1930), en el que ubica acertadamente la revista en la transición entre el declive del ultraísmo y la consolidación de las poéticas posteriores. Soria Olmedo repasa sucintamente algunos de los textos críticos en la órbita de la vanguardia que aparecen en Alfar. En 1989 César Antonio Molina publicó en Vigo Prensa literaria en Galicia, cuyo segundo tomo dedicó un largo capítulo a Alfar, extraído del libro de 1984. La publicación definitiva de los materiales de la tesis de Molina tuvo lugar en 1990 bajo el título de Medio siglo de Prensa literaria española (1900-1950). En él aparece un apartado informativo sobre la trayectoria y principales colaboradores de la revista coruńesa. Existe también un documental de 30 minutos dedicado a Julio J. Casal, realizado por José Antonio Durán (responsable de la dirección y del guión) y Mateo Meléndez Chas (fotografía y montaje). El documental, titulado Julio J. Casal, o cónsulpoeta que creou Alfar, fue editado en A Coruña en 1989 por Televisión de Galicia. También en 1989 se defendió en la Universidad Complutense de Madrid la tesis doctoral de María Dolores Reimunde Noreña, titulada Hispanoamérica en las revistas gallegas (1914-1936), con mención a la revista Alfar.

\section{AÑOS NOVENTA: CAMBIO DE CONSIDERACIÓN Y RECUPERACIÓN DEL ASPECTO PLÁSTICO DE ALFAR}

Los efectos de la labor de Molina no tardaron en aparecer: los años noventa destacan por un cambio general en la valoración de la revista coruñesa y en su frecuente revisión desde la historia del arte. Lo primero puede apreciarse en la

\footnotetext{
3 de mayo de 1984, p. 37. Bonet ofrece una reseńa muy completa de los contenidos de la revista coruńesa, e informa de la aparición del libro de Molina. En el mismo periódico, tres meses antes, había aparecido una nota por la inicial M. que informaba de la aparición del facsímil: «Al margen", La Vanguardia, 9 de febrero de 1984, p. 38.
} 
obra de Rafael Osuna, autor de un conjunto importante de libros dedicados a las revistas españolas. En 1986 dividía el corpus comprendido entre 1918 y 1931 en "cuatro grandes revistas», «revistas menores», y "otras revistas». En este último grupo situaba a Alfar, junto con Mediodia, Nós, Hermes y Ronsel, entre otras. De la revista coruñesa decía:

De complicada fortuna editorial, dirigida por el uruguayo Casal, de gran irregularidad y longuísima vida -llegará hasta 1954-, cuyos avatares esperan análisis meticulosos, además del muy útil que Víctor G. de la Concha le ha dedicado. Alfar, añadamos, fue una revista notable, bola de cristal de muchas reverberaciones literarias -incluidas las vanguardistas- y de interés para los historiadores del arte; por ello no han de extrañar las varias consultas sustanciales que se han hecho de sus páginas a la búsqueda de originales perdidos o para constatación de diversos fenómenos. Pero Alfar se aleja de las costas españolas en 1927 y su desaparición señala la de este tipo de revista, del que la República ya no verá ejemplos. Alfar fue lo que pudo, pero no supo ser Cosmópolis, la revista del guatemalteco Gómez Carrillo ${ }^{16}$.

Un libro de 1993 muestra un cambio de valoración respecto a Alfar. Si en el anterior las "cuatro grandes revistas» eran España, La Pluma, Revista de Occidente y La Gaceta Literaria; en este serán tres: caen las dos primeras, probablemente por criterio cronológico, y aparece Alfar, de la que de todos modos muestra un conocimiento indirecto, y de la que no llegaría a ocuparse en ninguno de sus libros posteriores:

Menos polémica [que Revista de Occidente] es Alfar, también más interiorizada en sus reductos literarios, que desde La Coruńa dirigía el uruguayo Julio J. Casal, y para cuya génesis se precisa conocer el trayecto preliminar de Vida (cinco números de julio 1920 a septiembre 1921) y, sobre todo, Boletín de Casa América-Galicia, cuyo título se transmutó varias veces hasta venir a dar en el de Alfar a partir del número 33 (octubre 1923). La nómina de sus colaboradores es tan extensa e importante que el manejo de sus 62 números españoles (hasta agosto-septiembre 1927, luego poseyó una nueva órbita americana hasta 1955-56), se hace totalmente obligatorio ${ }^{17}$.

La dimensión del aspecto plástico de la revista también empezó a ser reivindicada en los años noventa. En 1992 un conjunto de exposiciones y publicaciones supusieron un auténtico boom en torno a la figura de Rafael Barradas - principal colaborador plástico de la revista Alfar-como uno de los renovadores del arte español de los años veinte. Tal reivindicación contribuyó a la recuperación del aspecto plástico de Alfar $^{18}$. Sin duda, tanto la revalorización

16. Rafael Osuna, Las revistas españolas entre dos dictaduras: 1931-1939, Valencia, Pre-Textos, 1986.

17. Rafael Osuna, Las revistas del 27, Valencia, Pre-Textos, 1993.

18. Enric Jardí publicó Rafael Barradas a Catalunya i altres artistes que passaren la mar, Barcelona, Generalitat de Catalunya, con menciones a Alfar, aunque con varios errores en las fechas. Ese mismo año la Galería Jorge Mara editaba el catálogo de su exposición Rafael Barradas, con textos de Raquel Pereda, María Jesús García Puig y Rafael Santos Torroella. También de 1992 es el catálogo de la exposición Barradas: Exposició antològica, celebrada en 1993 en Madrid, Zaragoza y L'Hospitalet de Llobregat. El catálogo de la exposición contiene textos de Jaime Brihuega, Ángel Kalenberg, Rafael Santos Torroella, Concha Lomba, Andrés Peláez, Francesc 
de Alfar como la recuperación de su patrimonio plástico deben mucho al trabajo de Molina. Su colaborador en la edición facsimilar, Juan Manuel Bonet, se convertiría a partir de los noventa en uno de los grandes reivindicadores de la revista coruñesa. En 1995 Bonet publicó su imprescindible Diccionario de las vanguardias en España (1907-1936), en el que además de la entrada obligada a la revista, señala las publicaciones en las que colaboraron los autores reseñados, entre ellas Alfar. Al año siguiente coordinó junto a Carlos Pérez el catálogo de la exposición El ultraísmo y las artes plásticas celebrada en el IVAM de Valencia, en el que aparece la revista como uno de los principales documentos de las manifestaciones plásticas ultraístas. Ese mismo año se celebró en el Museo Nacional Centro de Arte Reina Sofía la magnífica exposición Arte moderno y revistas españolas 1898-1936, cuyo catálogo contiene textos muy útiles para el estudio de las revistas del periodo, entre los que destaca «Tipografías despobladas. El arte nuevo y las revistas de creación entre el novecentismo y la vanguardia. 1918-1930» de Eugenio Carmona, que dedica unas páginas espléndidas a la revista Alfar $^{19}$. Tales exposiciones coincidieron en el tiempo con otra que tuvo lugar en Madrid y Bilbao, centrada en La Sociedad de Artistas Ibéricos, y el arte español de 1925, a cargo de Jaime Brihuega y Concha Lomba. Alfar había dedicado en 1925 un número monográfico a la exposición que ese año realizó la entidad, y la mayoría de sus promotores fueron colaboradores de la revista. Por ello el estudio de la SAI tiene en Alfar un documento inexcusable. En 1997 se defendía en la Universidad Complutense de Madrid la tesis doctoral de Javier Pérez Segura, dedicada también a La Sociedad de Artistas Ibéricos (1920-1936), con presencia destacada de textos publicados en Alfar.

También en los noventa aparecieron algunos significativos trabajos de María Victoria Carballo-Calero. Autora de un texto meritísimo por su temprana publicación en 1983 (Carballo-Calero 1983), de elaboración previa a los trabajos de Molina, Carballo-Calero ha ido dedicando estudios a las revistas coruñesas de creación que precedieron y convivieron con Alfar, destacando sobre todo su aspecto plástico. De finales de los noventa son su discurso de ingreso en la Real Academia de Bellas Artes «La revista Vida, una aventura antes de Alfar» (1997) y el artículo «Luís Huici e a revista Luz, un dos precedentes de Alfar (A Coruña, Xullo de 1922)» (1999). El catálogo de la exposición Francisco Bores. El ultraísmo y el ambiente madrileño 1921-1925 celebrada en 1999 en la Residencia de estudiantes contiene textos de Eugenio Carmona, Javier Tusell y Juan Manuel Bonet de gran interés para el estudio de Alfar y su mundo. También en 1999 Rosa María Grillo incursionaba en la etapa uruguaya de Alfar con un libro sobre los años que en ese país pasó Bergamín: Exiliado de si mismo: Bergamin en Uruguay 1947-1954. Un capítulo titulado "Alfar entre La Coruña y Montevideo" presenta diez páginas sobre las publicaciones de Bergamín en la etapa uruguaya de la revista.

Miralles y Eugenio Carmona.

19. Carmona Eugenio, 1996, "Tipografías desdobladas. El arte nuevo y las revistas de creación entre el novecentismo y la vanguardia. 1918-1930», Arte Moderno y Revistas españolas. 1898-1936, Madrid, Museo Nacional Centro de Arte Reina Sofía, 63-102. 


\section{LA REVISTA ALFAR EN el SIGLO XXI}

Este nuevo siglo ha visto cómo los estudios sobre Alfar incorporaban perspectivas novedosas, provenientes de los estudios transatlánticos y los Iberian studies, que se sumaban a otras de carácter tradicional. El año 2000 vio la aparición de varios trabajos vinculados con Alfar. Andrés Sánchez Robayna escribió acerca de la presencia del poeta canario Alonso Quesada en la revista: «Sobre la génesis de "Los caminos dispersos" de Alonso Quesada: las versiones de Alfar». Quesada publicó considerablemente en la revista de Casal, de quien era amigo, y regentaba en Canarias una de las dos únicas librerías que se encargaba de las subscripciones de Alfar. Ana Lía Rey y Fernando Diego Rodríguez vieron publicada su ponencia «La revista Alfar. Una vanguardia en los márgenes», pronunciada el año anterior en el I Congreso Internacional de Historia Gallega de Buenos Aires. Eva Valcárcel publicó La Vanguardia en las revistas literarias, con un capítulo dedicado a "La poesía hispanoamericana en la revista Alfar hasta 1923». A pesar de lo que promete el título, el capítulo consta apenas de 10 páginas y presenta una elección arbitraria de escritores hispanoamericanos, cuya presencia en Alfar simplemente queda reseñada. El catálogo de la Biblioteca del Ibero-Amerikanisches Institut de Berlín fecha cerca del año 2000 el texto de Andrea Ayala Flores titulado «La revista Alfar y el discurso hispanoamericanista en Galicia». El documento, de apenas nueve páginas y de un carácter escolar, menciona alguna de las actividades institucionales de carácter hispanoamericanista reseñadas en Alfar. También del año 2000 es Órficos y ultraistas. Portugal y España en el diálogo de las primeras vanguardias literarias (1915-1925) de Antonio Sáez Delgado. El extenso libro dedica una página y media a la presencia de la literatura portuguesa en Alfar.

La revista coruñesa no vuelve a ser citada hasta 2003, cuando se presentó en las IX Jornadas Inter-escuelas del Departamentos de Historia Universidad Nacional de Córdoba, en Argentina, la ponencia «Revista Alfar. Regionalismo y vanguardias entre Galicia y el Plata en los años veinte», escrito en colaboración por Ana Lía Rey y Fernando Diego Rodríguez. Se trata de un texto muy sugerente, que trabaja los vínculos entre temática autóctona y formato vanguardista en producciones artísticas de ambos lados del Atlántico presentes en Alfar $^{20}$. En noviembre de 2004, un monográfico de la revista Quimera dedicado a «Las revistas literarias del siglo $\mathrm{XX}_{\text {» vuelve sobre la revista coruñesa. }}$ Sus coordinadores, Domingo Ródenas y Fernando Valls, consideraron que Alfar merecía figurar, junto con Prometeo, España, Litoral, Verso y Prosa, La Gaceta Literaria, Revista de Occidente y Cruz y Raya, como una de las revistas más destacadas del primer tercio de siglo, edad dorada de las publicaciones periódicas. Las dos páginas que le dedica Fidel López Criado son muy

20. Existe traducción al gallego: Ana Lía Rey y Fernando Diego Rodríguez, "Alfar. Rexionalismo e vangardas entre Galicia e o Plata» en Grial. Revista Galega de Cultura, tomo XLIX, n 191, julio-agosto-septiembre de 2011. 
completas y correctas -excepto por la inclusión de Lorca, Azaña y Castelao en la nómina de colaboradores-, aunque tan escaso espacio no puede albergar la dimensión americana y plástica de la revista. Ese mismo año el ayuntamiento de L'Hospitalet de Llobregat promovió la exposición Rafael Barradas, 1914$1929^{21}$. Al ańo siguiente, Javier San José Lera publicó «La imagen poética en la década prodigiosa (1920-1930). Teoría y Práctica», un muy buen capítulo que trabaja con textos críticos aparecidos en la revista coruñesa. También en 2005, María Victoria Carballo-Calero publicó «Gráfica, revista quincenal ilustrada (A Coruña, 1922), otra aventura antes de Alfar». En 2007, los dos grandes pintores uruguayos vinculados a la revista fueron motivo de la exposición $A$ Vangarda cotiá. Torres García e Barradas. 1917-1929, comisariada por Xosé Carlos Valle Pérez, que tuvo lugar en el Museo de Pontevedra.

Entre 2008 y 2011 María Victoria Carballo-Calero dirigió en la Universidade de Vigo el proyecto de investigación La ilustración artística en las editoriales vanguardistas gallegas: 1880-1936. Digitalización y catalogación de imágenes para la creación de una base de datos, financiado por el Ministerio de Ciencia e Innovación, que digitalizó y subió a la red muchas de las imágenes reproducidas en la revista Alfar. En este marco aparecieron algunos textos vinculados a Alfar, como «El Arte Nuevo y las revistas de creación en Galicia (1918-1936). Ronsel (Lugo, 1924), una revista ecléctica», escrito por la directora del proyecto, que cerraba así el ciclo de las revistas coruñesas que prefiguran Alfar; o "Sonia Delaunay \& Alfar: pasajes de una relación singular», de Susana Cendán. También en 2008 aparecieron dos artículos de gran interés. Marisa Martínez Pérsico publicó «Vibracionismo pictórico, ultraísmo literario. Ecos de un diálogo trasatlántico en la revista Alfar» en Revista Nuestra América, y Alicia Torres «Un consulado de poesía. Julio J. Casal entre Galicia y Uruguay», en Anuario del Centro de Estudios Gallegos. Ambos textos son imprescindibles para el estudio de la etapa española de la revista. En 2009 aparecía en el Boletín RAMÓN un artículo de Ester Lorenzo García titulado "Ocho artículos de Ramón Gómez de la Serna en Alfarn, en el que contrasta las colaboraciones del escritor madrileño en Alfar con sus versiones definitivas.

$\mathrm{Al}$ otro lado del Atlántico se dio un nuevo flujo de menciones a la revista y a su director. El 23 de octubre de 2009 el periódico montevideano El País publicaba "Por los tiempos de Alfar», un artículo de Álvaro Casal, sobrino del escritor, a raíz de una conferencia pronunciada por el mismo el 23 de marzo de 2009 en El Cairo. El mismo rotativo publicó el 9 de septiembre de 2010 una miscelánea de Rubén Loza Aguerrebere acerca del poeta y diplomático y su revista. El texto comentaba elogiosamente la iniciativa del profesor uruguayo Walter Rela, quien difundió ese mismo año a través de la red una copia digital de sus ejemplares. Estos números, pertenecientes a la etapa uruguaya de la revista (1929-1954), y que se encontraban en la web del profesor Rela ${ }^{22}$,

21. El catálogo contiene textos de María José González Madrid, Enrique Fuster del Alcázar y Eva Virgili Carbonell.

22. La página http://www.walterrela.com cayó en desuso tras el fallecimiento de su 
aparecen acompańados por una recopilación de cuatro textos breves que homenajean a la revista y a Julio J. Casal. Dos de ellos fueron escritos para la ocasión por el propio Walter Rela y por Nigel Dennis, a los que se añadió la comentada nota de Álvaro Casal y el libro de Selva Casal Mi padre Julio J. Casal, de 1987. También en la red, el portal «Publicaciones Periódicas del Uruguay» (http://www.periodicas.edu.uy/indice.php), coordinado por Lisa Block de Behar, ofrece varios números digitalizados de la etapa uruguaya de Alfar, ampliados en su nueva ubicación Anáforas (http://anaforas.fic.edu.uy/jspui/ handle/123456789/13) con la digitalización del facsímil de la primera etapa. Según informa el portal, los números provienen de la colección personal de Selva Casal, digitalizados por la Biblioteca Carlos Real de Azúa ${ }^{23}$.

En 2012 Marisa Martínez Pérsico defendió su tesis doctoral, titulada $A$ su imagen y caricatura. Crónicas noveladas del ultraismo por Rafael Cansinos Assens, Norah Lange y Leopoldo Marechal, en el Departamento de Literatura Espańola e Hispanoamericana de la Universidad de Salamanca, que dedica un capítulo muy riguroso a la revista. La misma autora publicó ese mismo año La gloria y la memoria. El Ultraísmo iberoamericano "suivant les traces» de Rafael Cansinos Assens. También en 2012 apareció un capítulo de libro de Jorge Olivera, titulado "La figura de Julio J. Casal a través de su epistolario», en el volumen colectivo editado por Carmen de Mora y Alfonso García Morales: Migraciones Intelectuales: escritores hispanoamericanos en España (1914-1939). La última publicación importante en relación al estudio de la revista Alfar fue el volumen Julio J. Casal (1889-1954). Alfarero y poeta entre dos orillas, publicado en julio de 2013 por Biblioteca Nacional de Uruguay, editado por Carlos García, responsable de la edición de numerosos epistolarios de autores españoles de la primera mitad del siglo XX, y Pilar García Sedas, autora de un libro sobre la relación personal y epistolar de Rafael Barradas y Joaquín TorresGarcía $^{24}$. El volumen ofrece una introducción biográfica a Julio J. Casal, la más completa hasta la fecha, y una selección de las cartas conservadas en el archivo Julio J. Casal de la BNU, entre otros materiales. En muchos casos las cartas recibidas por Casal han sido completadas con las que él mismo escribió a sus corresponsales, conservadas en distintos archivos europeos y americanos. A pesar de que el trabajo no es completo y de que se centra en la figura del director, constituye una referencia fundamental para cualquier acercamiento a la revista Alfar. El último trabajo relevante para el estudio de la revista coruñesa del que tenemos constancia es el catálogo de la exposición Barradas. Colección $M N A V$, celebrada en el Museo Nacional de Artes Visuales de Uruguay, aparecido en Montevideo en junio de 2013. El catálogo contiene un texto de Juan Manuel Bonet.

animador, pero fue recuperada en 2017 por el equipo del blog autores.uy: https://web.archive.org/web/20130719085129/http://walterrela.com/

23. La breve información que proporciona la web sobre Alfar no está exenta de errores comunes: ubica el inicio de Alfar en el no 33 de la publicación coruñesa y no en el 32; y considera que su primera etapa fue la revista Vida.

24. Pilar García-Sedas, Joaquim Torres-García i Rafael Barradas. Un diàleg escrit: 1918-1928, Barcelona, Publicacions de l'Abadia de Montserrat, 1994. 
En los últimos tiempos hemos visto un renovado interés por Alfar, que se traduce en el aumento de las menciones a la revista. Los títulos señalados son buena muestra del múltiple interés que la revista despierta, así como de la diversificación de los estudios que la tratan. Sin embargo, ésta todavía se resiste a un estudio integral. Justamente aquello que la consolida como referente inexcusable de la época -su largo recorrido, su eclecticismo y sus múltiples aspectos, plástico y literario, americano, ibérico, y europeo- diversifica el interés de los investigadores a la vez que convierte la realización de un estudio completo en una tarea compleja. No tenemos noticia de que el pasado 2014, cuando se cumplieron 60 años de la muerte de su director, haya dado ninguna novedad sobre Alfar. En este año se cumplieron también los 30 años de la aparición de La revista Alfar y la prensa literaria de su época (1920-1930) de César Antonio Molina, que a día de hoy todavía sigue siendo el principal estudio sobre Alfar. El interés del libro sigue vigente, pero cabe señalar que no recoge la dimensión plástica de la revista, ni las tensiones políticas y estéticas en las que participó Alfar en los distintos campos intelectuales en los que intervino, fuera en la Península Ibérica o en el Río de la Plata. Por todo ello se impone la necesidad de un estudio integral de la revista, que incorpore su aspecto plástico y literario, que describa de forma rigurosa su génesis -fuente de tantos equívocos que se van perpetuando- y que permita valorar su justa importancia en relación con los campos intelectuales en los que participó, más allá de la relevancia de sus colaboradores. Los trabajos aquí destacados constituyen en este sentido un valiosísimo acervo sin el cual la revista pasaría todavía hoy desapercibida, y deben ser el punto de partida fundamental para todo el que quiera sumergirse en la fascinante revista coruñesa.

\section{Bibliografía}

Bonet, Juan Manuel, 1995, Diccionario de las vanguardias en España (1907-1936). Madrid, Alianza.

Bonet Juan Manuel (Coord.), 1996, El ultraismo y las artes plásticas. Valencia, IVAM. Bonet Juan Manuel, 2013, "Rafael Barradas, ultraísta» en Barradas. Colección MNAV. Montevideo, Museo Nacional de Artes Visuales, 18-25.

Bozal Valeriano, 1966,, "La renovación artística de 1925 en España», Cuadernos Hispanoamericanos, Madrid, no 194, 248-258.

Carballo-Calero María Victoria, 1983, "Dibujantes orensanos en la revista "Alfar" " en Memoria 1982 del Museo de Pontevedra, Pontevedra, Patronato del Museo de Pontevedra.

Carballo-Calero María Victoria, 1999, "Luís Huici e a revista Luz, un dos precedentes de Alfar (A Coruña, Xullo de 1922)», Museo de Pontevedra, LIII.

Carballo-Calero María Victoria, 2005, "Gráfica, (revista quincenal ilustrada, La Coruña, 1922), otra aventura antes de Alfar», en Susana Reboreda Morilla (coord), 
Homenaxe á profesora Lola F. Ferro. Estudios de Historia, Arte e Xeografia, Vigo, Universidade de Vigo, 105-118.

Carballo-Calero María Victoria, 2009, «El Arte Nuevo y las revistas de creación en Galicia (1918-1936). Ronsel (Lugo, 1924), una revista ecléctica», Abrente, Vigo, no 40-41, 305-323.

Carmona Eugenio (cord.), 1999, Francisco Bores. El ultraismo y el ambiente madrileño 1921-1925, Madrid, Residencia de Estudiantes.

Casal Muñoz Selva, 1987, Mi padre Julio J. Casal, Montevideo, Biblioteca Alfar, 1987, $35 \mathrm{pp}$.

Cendán Susana, 2011, "Sonia Delaunay \& Alfar: pasajes de una relación singular», Abrente, A Coruña, no 42-43, 401-415.

García Carlos y García Sedas Pilar, 2013, Julio J. Casal (1889-1954). Alfarero y poeta entre dos orillas, Montevideo, Biblioteca Nacional de Uruguay.

García de la Concha Víctor, 1971, "Alfar, historia de dos revistas literarias», Cuadernos Hispanoamericanos, no 255, Madrid, 500-535.

Cossío José María de, 1944, «Prólogo» en Fernando Villalón, Poesías, Madrid, Editorial Hispánica, 15-16.

Cossío José María de, 1970, "Recuerdos de una generación poética», en Homenaje universitario a Dámaso Alonso reunidos por los estudiantes de Filología Románica. Curso 1968-1969, Madrid, Gredos, 189-202.

Geist Anthony Leo, 1980, La poética de la generación del 27 y las revistas literarias: de la vanguardia al compromiso (1918-1936), Madrid, Guadarrama.

González María José (et al.), 2004, Rafael Barradas, 1914-1929, L’Hospitalet, Ajuntament de L'Hospitalet.

Grillo Rosa María, 1999, Exiliado de sí mismo: Bergamín en Uruguay 1947-1954, Lleida, Universitat de Lleida.

Litvak Lily, 1985, "Alfar (Revista de Casa América-Galicia) 1922-1929», Hispanic Review, vol. 53, n 3, verano, 380-381.

López Criado Fidel, 2004, "Alfar», Quimera. Revista de Literatura, n 250, noviembre de 2004, 28-29.

Lorenzo García Ester, 2009, "Ocho artículos de Ramón Gómez de la Serna en Alfar», Boletín RAMÓN, no 19, primavera (de Buenos Aires) 3-11.

Losada S. Miguel, 1988, «Presencia de la literatura hispanoamericana en las revistas españolas de vanguardia: 1918-1939", Anales de literatura hispanoamericana, no 17, Madrid, 41-59.

Martínez Pérsico Marisa, 2008, «Vibracionismo pictórico, ultraísmo literario. Ecos de un diálogo trasatlántico en la revista Alfan», Revista Nuestra América, no 6, Agostodiciembre de 2008, 185-202.

Martínez Pérsico Marisa, 2012, La gloria y la memoria. El Ultraísmo iberoamericano «suivant les traces» de Rafael Cansinos Assens, París, Éditeur BoD.

Molina César Antonio (ed.), 1983, Alfar: Revista de Casa América Galicia (19201927), La Coruña, Nós.

Molina César Antonio, 1984, La revista Alfar y la prensa literaria de su época (19201930), La Coruña, Nós. 
Molina César Antonio, 1988, "Alfar: una revista entre dos mundos», Revista de Occidente, no 86-87, julio-agosto de 1988.

Molina César Antonio, 1989, Prensa literaria en Galicia, Vigo, Edicións Xeraiz de Galicia, 2 volúmenes.

Molina César Antonio, 1990, Medio siglo de Prensa literaria española (1900-1950), Madrid, Endymion.

Mora Carmen de y García Morales Alfonso (eds.), 2012, Viajeros, diplomáticos y exiliados. Escritores hispanoamericanos en España (1914-1939), vol. II, Bruselas, Peter Lang.

Ortiz Saralegui Juvenal, 1955, Diálogo con Julio J. Casal, Montevideo, Cuadernos de Julio Herrera y Reissig.

Rey Ana Lía y Rodríguez Fernando Diego, 2000, «La revista Alfar. Una vanguardia en los márgenes", Actas del I Congreso Internacional de Historia Gallega, Buenos Aires.

Sáez Delgado Antonio, 2000, Órficos y ultraistas. Portugal y España en el diálogo de las primeras vanguardias literarias (1915-1925), Mérida, Editora Regional de Extremadura.

San José Lera Javier, 2005, «La imagen poética en la década prodigiosa (1920-1930). Teoría y Práctica», en Praestans Labore Víctor: homenaje al profesor Victor García de la Concha. Salamanca: Ediciones Universidad Salamanca, 399-421.

Sánchez Robayna Andrés, 2000, «Sobre la génesis de "Los caminos dispersos" de Alonso Quesada: las versiones de Alfar», Estudios canarios: Anuario del Instituto de Estudios Canarios, no 45, 73-94.

Santos Torroella Rafael, 1952, Medio siglo de publicaciones de poesía en España. Catálogo de revistas, I Congreso de poesía, Segovia / Madrid.

Soria Olmedo Andrés, 1988, Vanguardismo y crítica literaria en España (1910-1930), Madrid, Istmo.

Torre Guillermo de, 2001, Historia de las literaturas de vanguardia, Madrid, Visor.

Torres Alicia, 2008, "Un consulado de poesía. Julio J. Casal entre Galicia y Uruguay», Anuario del Centro de Estudios Gallegos, Montevideo, Universidad de la República, 19-48.

VV. AA, 1996, Arte Moderno y Revistas españolas. 1898-1936, Madrid, Museo Nacional Centro de Arte Reina Sofía, 63-102. 
